\title{
STUDY OF THE INUNDATION ANALYSIS OF FLASH FLOODS IN URBAN AREAS FOR RAINFALL IMPACT FORECASTING
}

\author{
SUK HO LEE, DONG HO KANG, KYUNG SU CHU \& BYUNG SIK KIM \\ Department of Urban and Environmental Disaster Prevention Engineering, \\ Kangwon National University, Republic of Korea
}

\begin{abstract}
Due to climate change, changes in weather such as heavy rains and typhoons have caused various disasters. In addition, the scale of damage is also increasing, which requires quantitative analysis. The purpose of this study is to analyze the impact of rainfall in a specific area and to analyze the secondary damage caused by flash flooding during heavy rains and to use it in forecasting. In order to calculate the depth of flooding due to heavy rain, a rainfall depth of $0-300 \mathrm{~mm}$ is increased by $20 \mathrm{~mm}$ intervals to produce flooding depth data according to rainfall and, using this, the rainfall-immersion depth relationship curve was developed. Using the developed curve equation, the rainfall (limit rainfall) causing the specific submersion depth $(10,20,50 \mathrm{~cm})$ was calculated, and the rainfall flood forecasting was performed in the target area based on the calculated threshold rainfall. The target areas were divided into grids of $1 \mathrm{~km} \times 1 \mathrm{~km}$ for the Sadangcheon basin, including the vicinity of Sadang Station, which was flooded due to heavy rains in 2011. The target of the second disaster was limited to urban flooding caused by flash floods in the Sadangcheon basin and model coupling techniques of the rainfall-leakage model (S-RAT) and the flood-campaign model (FLO-2D) were used to analyze urban flooding. The targets of the disaster were categorized into people, vehicles, and facilities, and the rainfall (threshold rainfall) that could cause damage to each target was calculated. In addition, the damage stage was divided into four stages by using the rainfall intensity (rainfall impact level). Based on the heavy rains that occurred in the Sadangcheon basin in July 2011, the results were compared with the forecast results due to the inundation status of the Sadang Station and the rainfall impact level.
\end{abstract}

Keywords: S-RAT, FLO-2D, coupling technique, threshold rainfall, heavy rain impact level.

\section{INTRODUCTION}

Recently, various disasters occur due to the change of weather due to climate change, and the damage scale is increasing. Meteorological phenomena and socio-economic impacts According to the inertia analysis, the most frequent and largest damages are the disasters. Meteorological phenomena that cause meteorological disasters are heavy rains and typhoons. In addition, the most common weather factor between heavy rain and typhoon is rainfall. Therefore, natural disasters in our country occur most frequently due to rainfall, and thus, we can minimize the damage to disasters by predicting and preparing for them in advance. Currently, the Meteorological Agency uses the ensemble prediction technique to predict future rainfall information. Ensemble prediction is a system that complements the limitations of deterministic prediction of a single numerical forecast and predicts the future probabilistically by performing several models with different initial conditions, physical processes, boundary conditions, etc. Using this, the Korea Meteorological Administration currently conducts forecasts for rainfall in various forms such as short-term, mid-term, longterm forecasts, neighborhood forecasts, national forecasts, and special reports. The biggest drawback of current forecasts, however, is that heavy rainfall forecasts are being made without considering regional characteristics because they only predict the absolute value of rainfall. Of course, there are additional forecasts for protecting facilities, paying attention to flooding, and preparing for flooding. To this end, the World Meteorological Organization has 
already identified the impact of disasters and established guidelines for forecasting services. Emphasis is placed on the importance of forecasts for weather agencies in each country. Weather forecasting countries, including the United Kingdom and the United States, have already implemented partial impact forecasts (Yeh [1]). The Flood Forecasting Centre (FFC) in the UK has created a user manual for forecasting flood impacts and has created a flood risk matrix to divide the flood risk stages into four stages [2]. In addition, in the United Kingdom, grid-based flood impact forecasts are carried out and grid-based impact forecasts are carried out using the G2G (grid to grid) model, which is a distributed model, to simulate flooding (Cole [3], Price et al. [4], Cranston et al.[5]).

In Korea, research for the impact forecast is underway. Kim et al. [6] explained the characteristics of impact forecasts and analyzed the current status and cases of impact forecasts in advanced countries and Lee [7] estimated the marginal rainfall causing flood damage, focusing on flood damage cases in Gangnam area.

Rainfall is also important in estimating rainfall for forecasting impacts, but rainfall is largely dependent on topography, i.e. the characteristics of the region (rivers, mountains, urban areas), land use, and soil. Depending on the region's drainage management system, various secondary damages can occur, such as urban flooding, landslides and flooding. Even for the same runoff, the impact of the runoff may vary between regions and time periods. Therefore, if the characteristics of the secondary and tertiary disasters caused by precipitation are identified, it is possible to predict the impact on actual damages, not the forecasts limited to rainfall.

The purpose of this study is to analyze the impact of rainfall in a specific area and to forecast the damage caused by flooding during the secondary damage caused by actual rainfall. In 2011, the target areas were divided into $1 \mathrm{~km} \times 1 \mathrm{~km}$ grids for three areas of Sadang-dong and Seocho-dong, which were affected by flooding due to torrential rains, to determine the limit rainfall causing specific flooding in each area. In order to estimate the Threshold Rainfall, the model coupling technique of rainfall-runoff model S-RAT (Kim et al. [8]) and flood overflow model FLO-2D [9] was used. Based on the estimated rainfall, the forecasting stage according to rainfall was divided into four stages. In fact, the intensive rainfall scenario that occurred around Sadang-dong and Seocho-dong in 2011 was applied. Inundation cases were compared and analyzed.

\section{RESEARCH METHOD}

This study is to develop a method of estimating the rainfall impact that causes constant flooding in each region and classifying the risk impact from heavy rainfall over time. The lowest mark is defined as the starting point of flooding in the grid where heavy rain damage occurred among the target areas, and the runoff amount is calculated at the lowest mark, and the amount of runoff is used as input data of the flood scope model to conduct inundation analysis to develop the depth-high water flow relationship curve. The developed rainfallsubmersion curve is used to produce marginal rainfall that causes a specific submersion depth. The critical grid for the critical rainfall was $1 \mathrm{~km} \times 1 \mathrm{~km}$, but in the runoff analysis, the watershed was calculated by dividing the basin based on the lowest elevation point in the $1 \mathrm{~km} \times 1 \mathrm{~km}$ grid, and the flooding depth was calculated by applying the calculated runoff to the immersion model. Using the simulation results, the rainfall-submerged depth curve was calculated using the maximum submerged depth in the $1 \mathrm{~km} \times 1 \mathrm{~km}$ grid. Therefore, the target grid of marginal rainfall is $1 \mathrm{~km} \times 1 \mathrm{~km}$, and the range applied to rainfall-flow and flooding simulation is the entire flood basin including the target grid. In addition, the threshold rainfall of each grid is calculated using the developed curve equation and the results 
are compared and analyzed using the rainfall scenario. The research procedure is shown in Fig. 1.

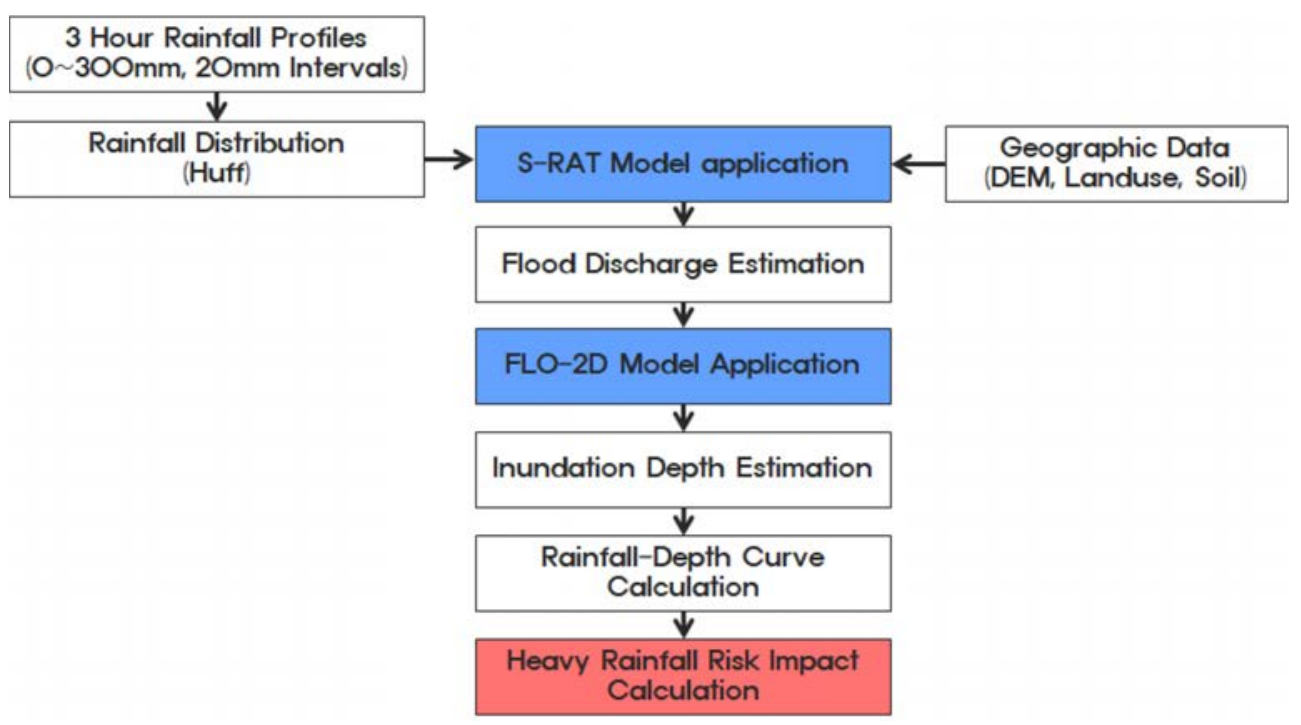

Figure 1: Study flow chart.

\section{THEORETICAL BACKGROUND}

\subsection{S-RAT}

The S-RAT (Spatial Runoff Assessment Tool) model is a distributed rainfall-runoff model developed by Kim et al. [8]. It is designed to simulate the spatial and temporal runoff changes in the watershed by calculating the balance. Most distributed hydrologic models also rely on GIS-related commercial packages, such as Arc-related software or IDRISH, to extract topographical parameters to be entered in the model, but S-RAT has its own parameters extracted and simplified input. The S-RAT model used the SCS curve number (CN) method to estimate the permeation and direct runoff for each grid. To do this, the soil map and land use are input and the $\mathrm{CN}$ value grid data is generated and calculated

$$
S(i, j)=254(100 / C N(i, j)-1),
$$

where $S(i, j)$ is the potential reserve; $C N(i, j)$ is $C N$ value per grid

$$
\frac{P_{n}[t,(i, j)]}{P[t,(i, j)]}=\frac{F[t,(i, j)]}{H S(i, j)},
$$

where $F[t,(i, j)]$ is the infiltration capacity of the infiltration reservoir (water content) (mm); $H S(i, j)$ is capacity of infiltration storage tank

$$
\begin{gathered}
I[t(i, j)]=P[t,(i, j)]-P_{n}[t,(i, j)], \\
\mathrm{W}[\mathrm{t},(\mathrm{i}, \mathrm{j})]=\frac{F[t,(i, j)]}{H S},
\end{gathered}
$$




$$
\mathrm{I}[\mathrm{t}(\mathrm{i}, \mathrm{j})]-\mathrm{W}[\mathrm{t},(\mathrm{i}, \mathrm{j})]=\frac{d F[t,(i, j)]}{d t},
$$

where $\mathrm{W}[\mathrm{t},(\mathrm{I}, \mathrm{j})]$ is subsurface spill ; $P_{n}[t,(i, j)](\mathrm{mm})$ is direct outflow, $H_{s}$ is a conceptual parameter as a dimensionless constant. Eqns (3)-(6) are used to calculate the governing equation of mass storage of the infiltration reservoir. Eqn (7) can be interpreted using the fourth-order Runge-Kutta method

$$
\frac{d F[t,(i, j)]}{d t}=-\frac{F[t,(i, j)]}{H S}-E[t(i, j)]+\mathrm{P}[\mathrm{t},(\mathrm{i}, \mathrm{j})]\left\{1-\frac{F[\mathrm{t}(\mathrm{i}, \mathrm{j})]}{H S(i, j)}\right\} .
$$

Fig. 2 shows a conceptual diagram of the grid water balance calculation of this model.

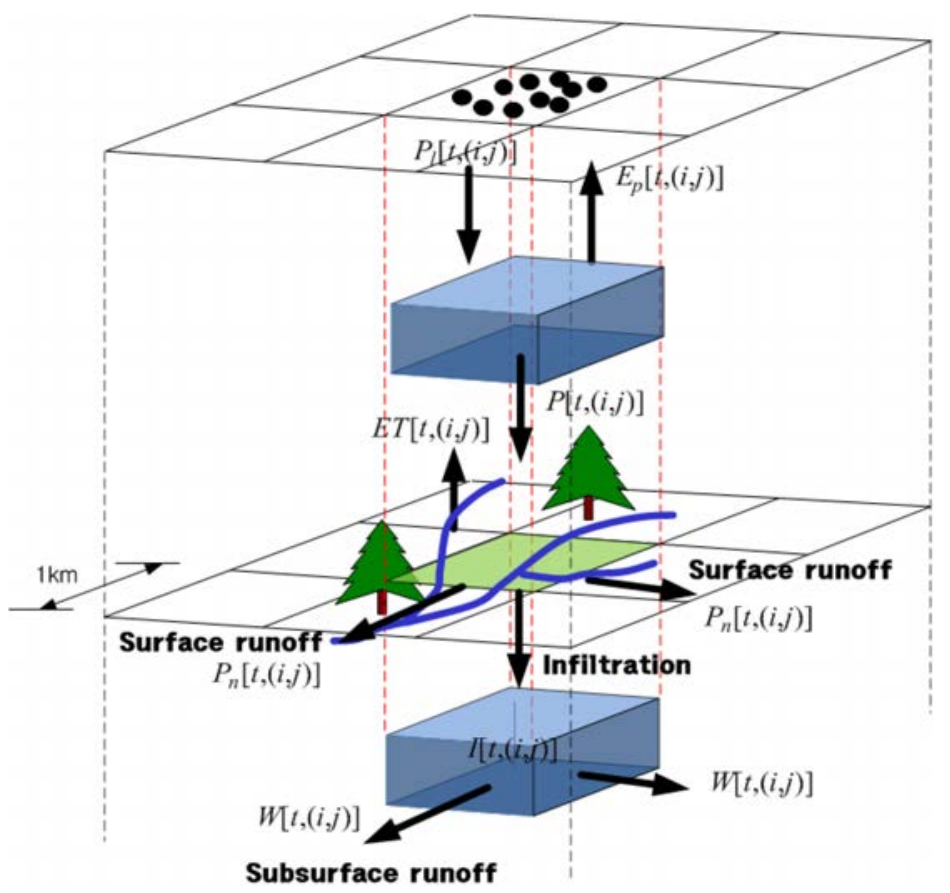

Figure 2: Conceptual diagram of grid water balance [8].

\subsection{FLO-2D}

The FLO-2D model was first developed in 1988 to identify insurance flooding areas in the US state of Colorado [9]. The FLO-2D model reproduces the tracing of the flood while preserving the volume. Basically, starting with surface flood simulations, components can be added to the simulation for various topographical requirements, flow obstructions in buildings, bridges, dikes, etc. in urban areas, and losses in flow paths. The FLO-2D model is certified by the US Federal Emergency Management Agency (FEMA), so it is highly reliable, and GDS, MAPPER ++, etc. can be used to automatically distinguish flooded areas. In addition, the results are processed as a graph, so it is easy to check space and time. The flow equation of FLO-2D is same as eqn (7), and it is based on continuous equation and momentum equation 


$$
\begin{gathered}
\frac{\partial h}{\partial t}+\frac{\partial h V}{\partial x}=i, \\
S_{f}=S_{0}-\frac{\partial h}{\partial x}-\frac{V}{g} \frac{\partial V}{\partial x}-\frac{1}{g} \frac{\partial V}{\partial x}=0,
\end{gathered}
$$

where $h$ is the depth of the flow, $V$ is the average velocity of one of the eight direction flows (x-directions) in the starting lattice, and $i$ is the excess rainfall intensity. $S_{f}$ is based on the Manning equation with a friction gradient.

Fig. 3 flows from eight flow directions at the top right are differentially distributed to adjacent grids according to the elevation difference. The distributed flow rate is distributed along the elevation difference with adjacent grids, moving along a constant pathway.

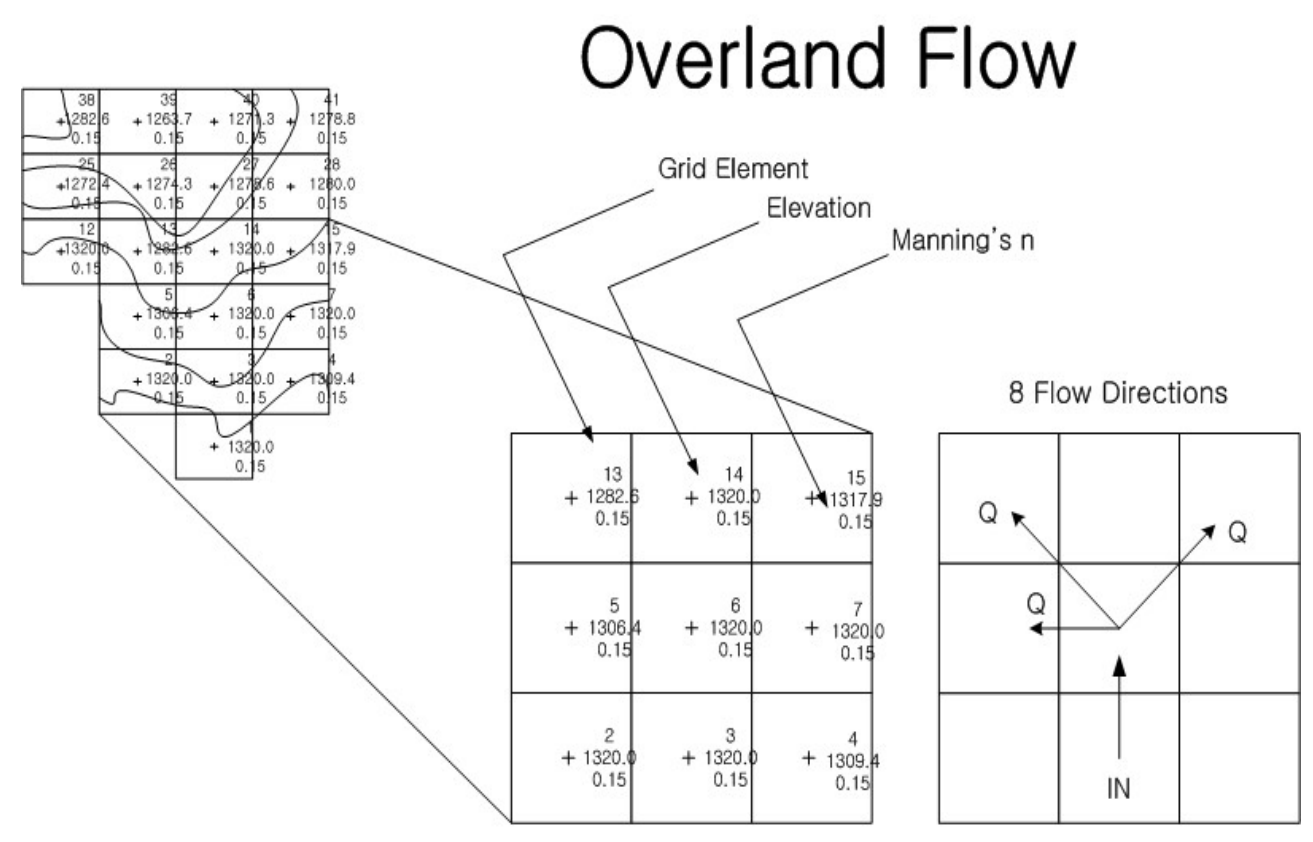

Figure 3: Discharge flux across grid element boundaries [9].

\section{APPLICATION AND RESULTS}

\subsection{Target area}

The area of this study was about $300 \mathrm{~mm}$ of heavy rainfall from 01:00 to 23:00 on 27 July 2011 at Sadangcheon, located in Dongjak-gu, Seoul, Korea. In order to analyze the damage, the submerged area was divided into grids of $1 \mathrm{~km} \times 1 \mathrm{~km}$ (Fig. 4).

\subsection{Construction of input data}

The data needed in the rainfall-runoff model are rainfall and terrain data (DEM, Landuse, Soil map). The 500 year probability rainfall of 3 hours in Seoul rainfall station is $243 \mathrm{~mm}$ [10]. Therefore, a total of 15 types of rainfall scenario were established by dividing 20 to $300 \mathrm{~mm}$ into $20 \mathrm{~mm}$ units. In order to distribute the total amount of rainfall in time series, 
Huff rainfall distribution method was used to convert the time series into rainfall data format [11]. we used the second quartile, which is considered to reflect the rainfall pattern of Korea, and the third quartile, which is the median of the quartile, to consider the extreme situation. The results of the third quartile rainfall scenario for the 3 hour sustainment time are shown in Fig. 5.

In order to calculate the surface flow direction and surface discharge of the target grid, subwatersheds including target grids were divided and spatial information of DEM, Landuse, and Soil map with $30 \mathrm{~m} \times 30 \mathrm{~m}$ resolution was constructed. The spatial information deployed is as shown in Fig. 6.

Data required for flood analysis using FLO-2D are the flood scope and the DEM. The runoff is calculated using the rainfall-flow model of the flood overflow flow, and the DEM uses the same spatial data as the DEM used in the rainfall-flow model.
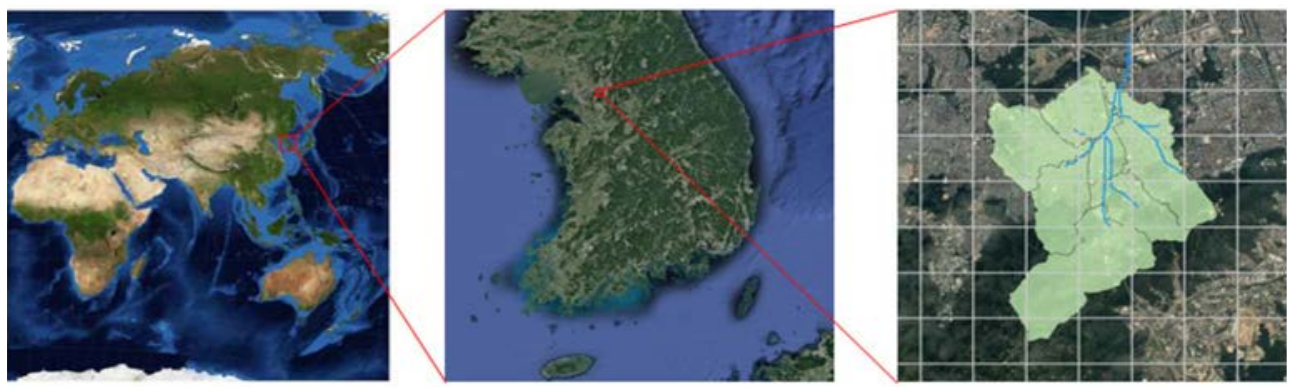

Figure 4: Study area.

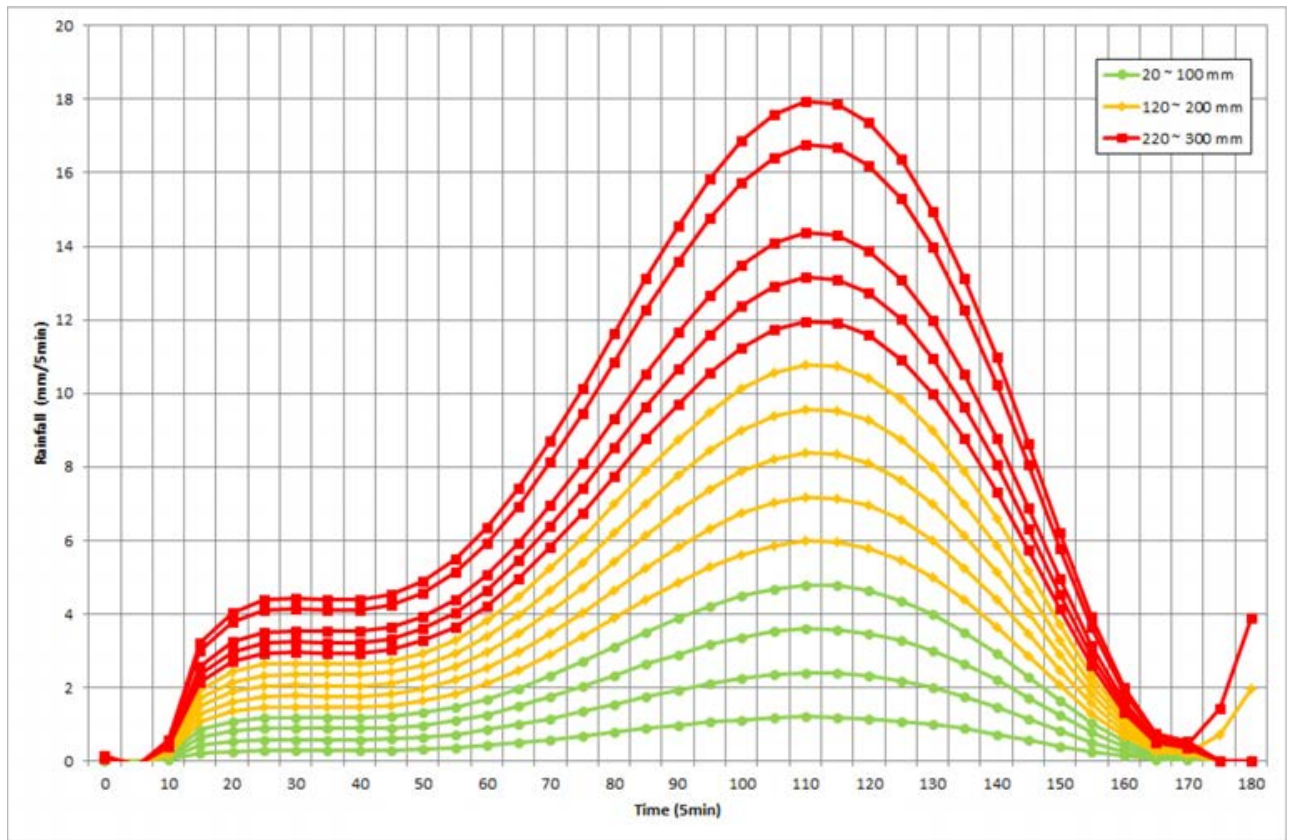

Figure 5: Rainfall scenarios with third quartile in the duration of $180 \mathrm{~min}$. 


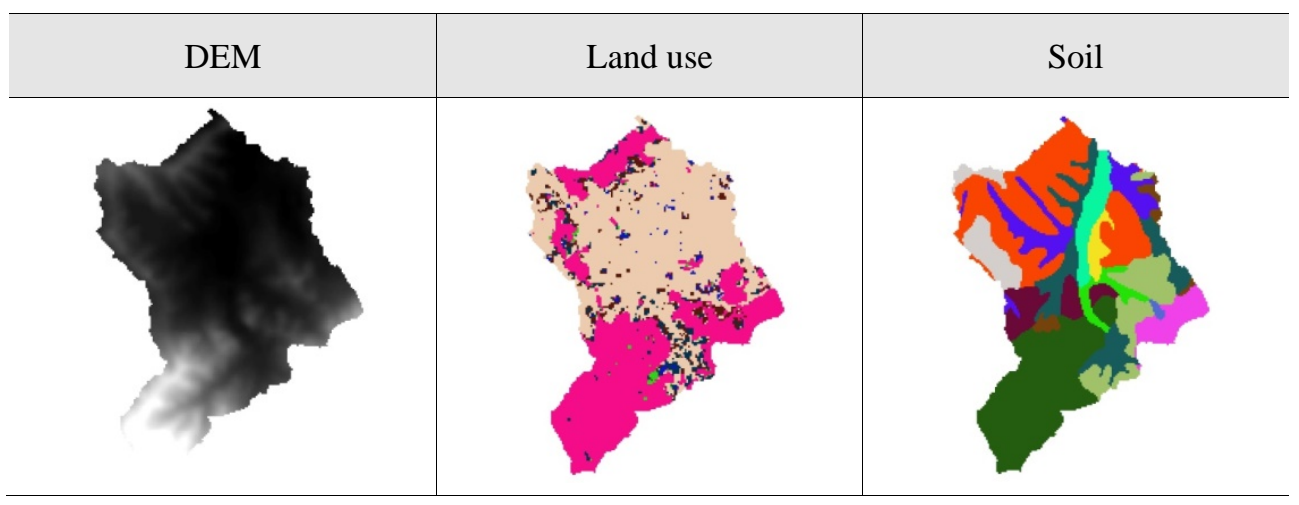

Figure 6: Topographic data.

\subsection{Application of rainfall-spill model (S-RAT)}

Using the set rainfall for each scenario, the S-RAT model is used. Rainfall-flow analysis of five basins was conducted. The resolution of the subwatershed is $30 \mathrm{~m} \times 30 \mathrm{~m}$, so the flow rate can be checked for each grid. The basic unit for impact prediction is $1 \mathrm{~km} \times 1 \mathrm{~km}$, and the reference point for application of the flooding model within the grid is defined as the lowest elevation point at the reference grid $(1 \mathrm{~km} \times 1 \mathrm{~km})$. In the case of the S-RAT model, once the watershed rainfall-runoff simulation is completed, the flow rate of the grid can be immediately identified on any grid. Fig. 7 is a grid of rivers forming during rainfall in the Sadangcheon basin. Calculate the amount of runoff from each grid using 15 types of rainfall in Fig. 5. The calculated discharge amount becomes the discharge flow rate from the flood control model and is used as the input value of the flood analysis. The release rate of No. 4, the final exit point of the basin, is as shown in Fig. 8.

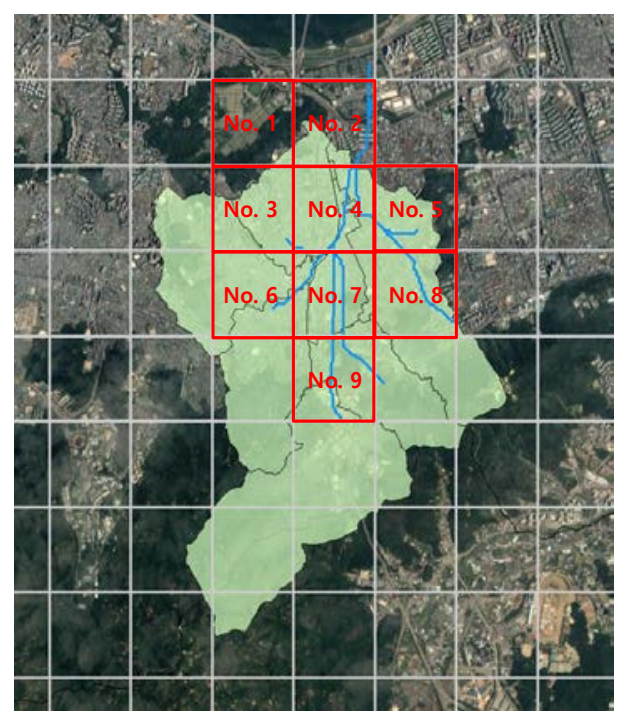

Figure 7: Basin for runoff model. 


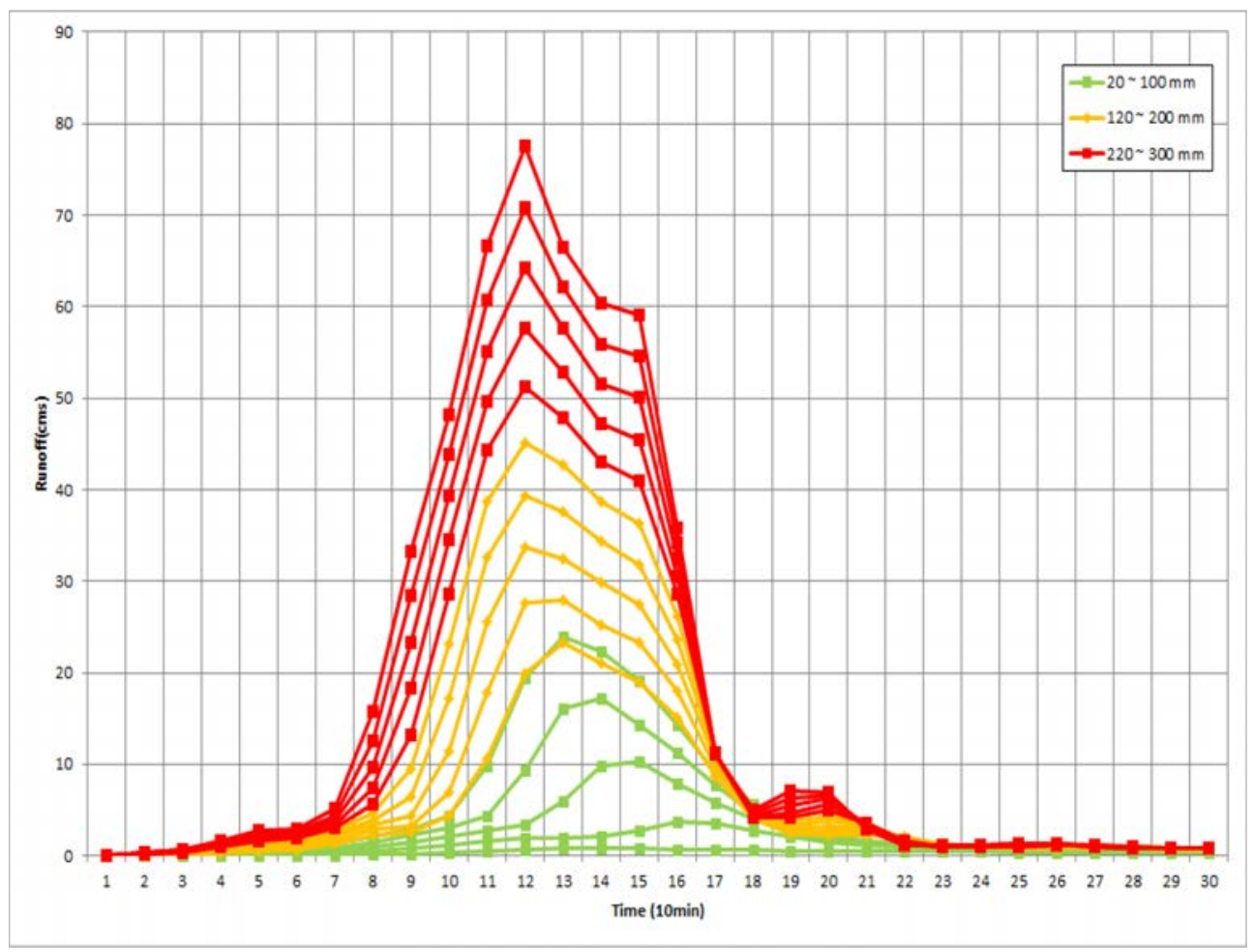

Figure 8: Result of runoff in study area.

\subsection{Flood campaign model (FLO-2D) application}

In order to simulate the depth of flooding, the runoff value from the analysis point calculated above was distributed to the minimum elevation of each grid over time. For more accurate simulation of flooding in urban areas, the flow rate through the sewer network from the surface runoff calculated by the rainfall-runoff model is used as an input to the flood overflow model (except for underground runoff). In the case of immersion analysis for forecasting the impact of the UK, the flooding capacity of five years was regarded as the flood protection capacity, and the immersion analysis was carried out using the flow rate excluding the flood protection capacity of five years from the runoff. According to the frequency of Korea's sewage system, design is currently underway based on the target rainfall for anti-disaster performance by the Ministry of Public Administration and Security, but the existing pipe network has been designed and constructed at frequencies between 5 and 15 years. In addition, the flooding around the Sadang station, which is the study area, also lacked the water supply capacity of the network, but it was also a factor that prevented the smooth water supply of the network due to manhole residues such as soil and leaves. Therefore, in this study, immersion analysis was carried out considering only surface runoff except ground runoff through sewer pipe network. Fig. 9 shows the rainfall-submerged depth curves of nine grids in the Sadangcheon basin, the analysis area, and shows the relationship between rainfall for each scenario and the submerged depth through the final submerged analysis. Using the recording curve produced in Fig. 8, the limit rainfall is calculated according to the flood depth. 


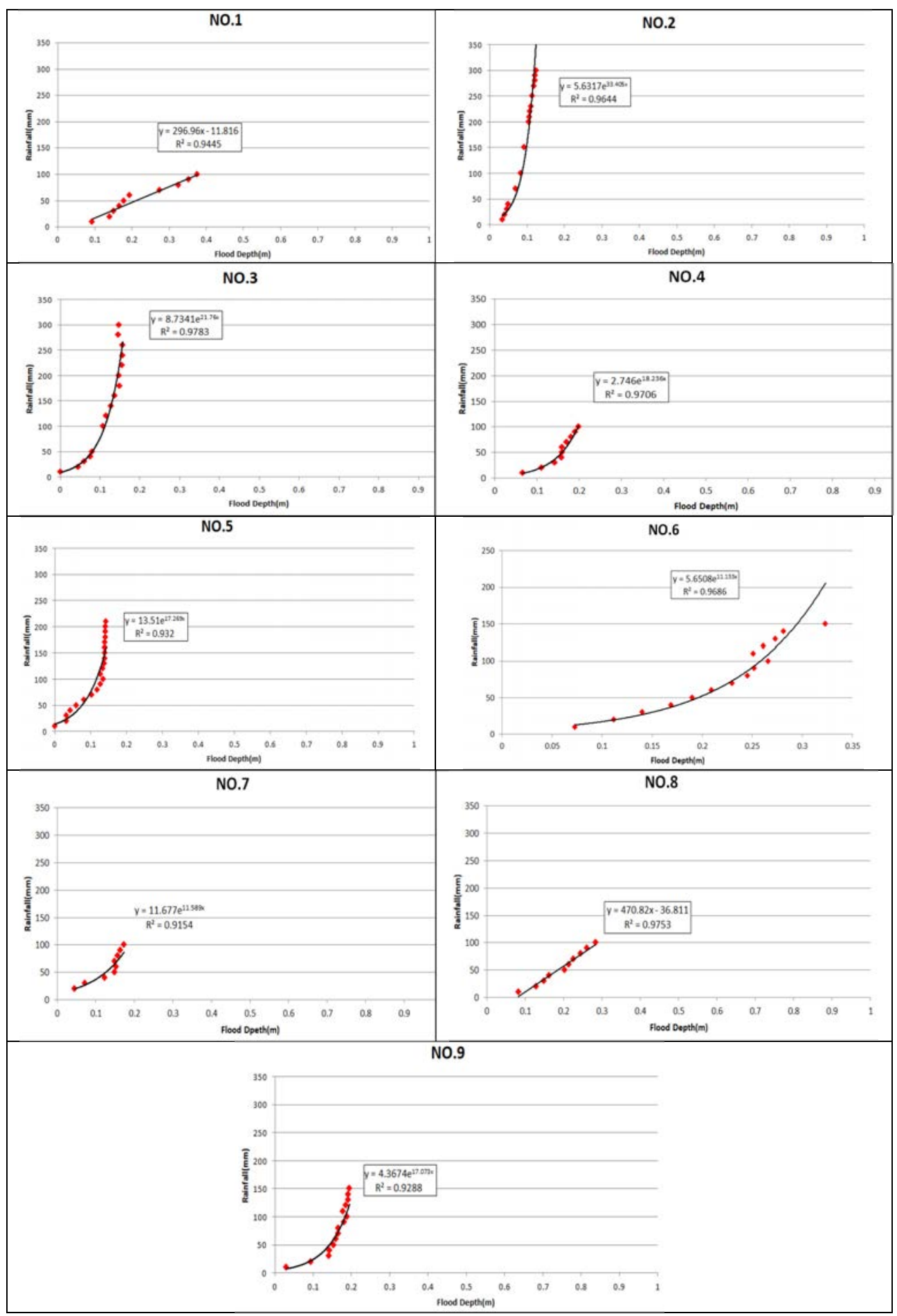

Figure 9: Rainfall-depth curve. 


\subsection{Estimation of threshold rainfall}

In order to forecast the impact of flooding due to rainfall, it is necessary to determine who will be affected by flooding and the depth of flooding that will be affected. In this study, the subjects of damage were defined as three cases: life, vehicle, and building.

Considering the relevant data, the rainfall impact level was set to four levels. The first stage is $0-10 \mathrm{~cm}$, which is considered to be inconvenient for walking, the second stage is $10-20 \mathrm{~cm}$, which is the improper height of passenger cars, and The third step is $20-50 \mathrm{~cm}$ considering the height of the installation waterproof plate, and the fourth step is determined to be more than $50 \mathrm{~cm}$ causing the flooding of the facility. And the rainfall-flood depth curve of Fig. 10 was used to estimate the marginal rainfall that induces submerged depths representing the boundary of each rainfall impact level (Table 1).
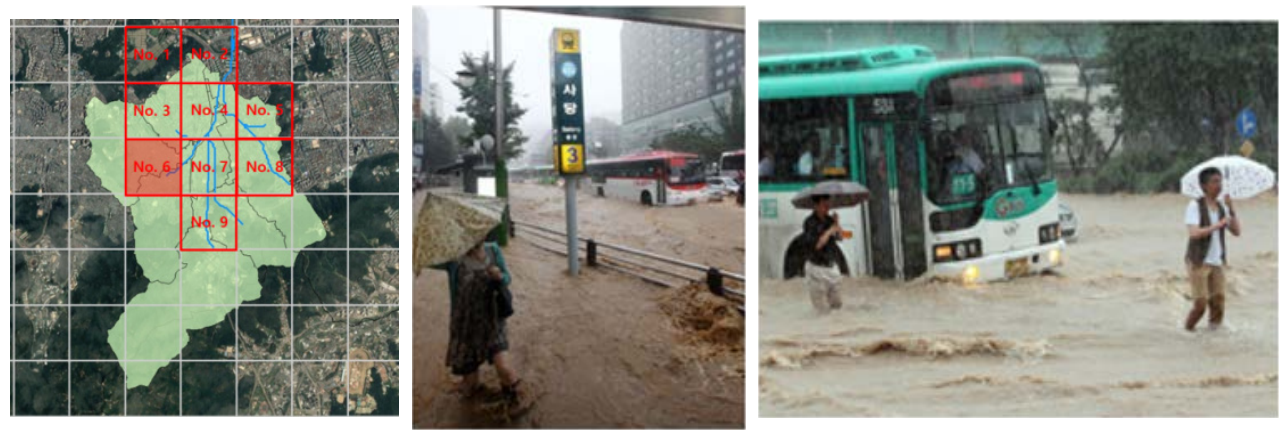

Figure 10: Study area and real case (No. 6).

Table 1: Calculation of critical rainfall and impact level.

\begin{tabular}{|c|c|c|c|c|c|c|c|c|}
\hline \multirow{2}{*}{ Grid } & \multirow{2}{*}{ Rainfall-depth curve } & \multicolumn{7}{|c|}{ Critical rainfall/impact level } \\
\hline & & $<$ & $10 \mathrm{~cm}$ & $\sim$ & $20 \mathrm{~cm}$ & $\sim$ & $50 \mathrm{~cm}$ & $<$ \\
\hline No. 1 & $y=296.46 x+188.92$ & \multirow{9}{*}{$\begin{array}{c}\text { Level } \\
1\end{array}$} & $17 \mathrm{~mm}$ & \multirow{9}{*}{$\begin{array}{c}\text { Leve1 } \\
2\end{array}$} & $105 \mathrm{~mm}$ & \multirow{9}{*}{$\begin{array}{c}\text { Level } \\
3\end{array}$} & - & \multirow{9}{*}{$\begin{array}{c}\text { Level } \\
\quad 4\end{array}$} \\
\hline No. 2 & $y=5.6317 e^{33.405 x}$ & & $76 \mathrm{~mm}$ & & $427 \mathrm{~mm}$ & & - & \\
\hline No. 3 & $y=8.7341 e^{21.76 x}$ & & $52 \mathrm{~mm}$ & & $200 \mathrm{~mm}$ & & - & \\
\hline No. 4 & $y=1355.9 x+84.598$ & & $37 \mathrm{~mm}$ & & $119 \mathrm{~mm}$ & & - & \\
\hline No. 5 & $y=13.51 e^{17.269 x}$ & & $10 \mathrm{~mm}$ & & $57 \mathrm{~mm}$ & & $199 \mathrm{~mm}$ & \\
\hline No. 6 & $y=521.13 x+93.267$ & & $23 \mathrm{~mm}$ & & $78 \mathrm{~mm}$ & & $244 \mathrm{~mm}$ & \\
\hline No. 7 & $y=1018.2 x+208.32$ & & $24 \mathrm{~mm}$ & & $133 \mathrm{~mm}$ & & - & \\
\hline No. 8 & $y=500.17 x+164.89$ & & $159 \mathrm{~mm}$ & & - & & - & \\
\hline No. 9 & $y=4.3674 e^{17.073 x}$ & & $32 \mathrm{~mm}$ & & $49 \mathrm{~mm}$ & & $72 \mathrm{~mm}$ & \\
\hline
\end{tabular}

\subsection{Study area application}

Based on the total rainfall, a comparative analysis was performed using the actual rainfall in the area of analysis. On 26-29 July 2011, Seoul suffered 34,152 victims, including 22 deaths 
and 39 injuries. During this period, the heavy rains, which occurred from 01:00-23:00 on the 27th July, were about $300 \mathrm{~mm}$, which caused large flooding damage in the areas of Sadangdong and Seocho-dong. Therefore, a 24 hour rainfall impact forecast was performed assuming the rainfall data during this period as a predicted rainfall scenario. The forecasting time was every 1 hour, and the rainfall impact level was calculated by comparing the marginal rainfall corresponding to the life, vehicle, and building based on the rainfall after 3 hours from the reference time. In the case of Sadang-dong Sadang Station (grid No. 6), flooding impact level 2 started from 03:00 and maximum flooding depth of $30 \mathrm{~cm}$ (three levels of heavy rain impact level) occurred after 19:00. As seen in Fig. 10, it affected walking and vehicle movements around Sadang Station.

Table 2: Result of rainfall impact level (No. 6).

\begin{tabular}{l|c|c|c|c|c|c|c|c|c|c|c|c}
\hline Time & $01: 00$ & $02: 00$ & $03: 00$ & $04: 00$ & $05: 00$ & $06: 00$ & $07: 00$ & $08: 00$ & $09: 00$ & $10: 00$ & $11: 00$ & $12: 00$ \\
\hline $\begin{array}{l}\text { Rainfall } \\
(\mathrm{mm})\end{array}$ & 0.98 & 14.71 & 42.14 & 77.42 & 60.16 & 62.90 & 59.88 & 115.6 & 159.3 & 140.4 & 85.75 & 29.15 \\
\hline Depth (cm) & 0 & 9 & 18 & 24 & 21 & 22 & 21 & 27 & 30 & 29 & 24 & 15 \\
\hline Impact level & - & 1 & 2 & 3 & 3 & 3 & 3 & 3 & 3 & 3 & 3 & 2 \\
\hline Time & $13: 00$ & $14: 00$ & $15: 00$ & $16: 00$ & $17: 00$ & $18: 00$ & $19: 00$ & $20: 00$ & $21: 00$ & $22: 00$ & $23: 00$ & - \\
\hline $\begin{array}{l}\text { Rainfall } \\
(\mathrm{mm})\end{array}$ & 19.70 & 10.48 & 14.49 & 6.35 & 7.85 & 7.55 & 0.00 & 2.82 & 1.11 & 0.00 & 0.98 & - \\
\hline Depth (cm) & 11 & 6 & 8 & 1 & 3 & 3 & 0 & 0 & 0 & 0 & 0 & - \\
\hline Impact level & 2 & 1 & 1 & 1 & 1 & 1 & - & - & - & - & - & - \\
\hline
\end{tabular}

\section{CONCLUSION}

Even though the same rainfall occurs, the depth of flooding in each region varies according to the topographic conditions and flood protection ability of the region. Therefore, if you know in advance the rainfall that causes a certain flooding depth in a particular area, you can use the predicted rainfall to proactively predict damage. In this study, for the prediction of heavy rain effects, we investigated the method of forecasting the damage effect using flooding depths in urban areas caused by heavy rains. Damage targets due to flooding were divided into population, traffic, and facilities, and the damage criteria for flooding were investigated and analyzed to create four-step Impact Levels according to the damage status, and the threshold rainfall causing marginal flooding at each stage was determined. Rainfall impact forecasts were carried out using real rainfall in the affected areas of Seodang-dong in Sadang-dong, assuming that the real rainfall was the predicted rainfall. Based on the immersion depth of each time, the rainfall impact level was assigned by comparing with the threshold rainfall and compared with the rainfall impact level and actual flood damage cases. As a result of the comparison, it was confirmed that the results of immersion analysis with time showed similar patterns according to the impact level. In many studies of disasters, risk is largely determined by three conditions: disaster, exposure and vulnerability. To analyze the risks of heavy rain effects and forecast their impacts, we analyze disasters (inundation depths) caused by heavy rains, estimate exposure and vulnerability by considering the spatial and spatial distribution of population, traffic, and facilities in each region. The final impact level should be calculated.

Up to now, the rainfall impact thresholds have been assigned based on the submerged depth only. Therefore, additional studies should be conducted on the values of 10, 20, and $50 \mathrm{~cm}$, which are the depths of heavy rain impact limits for each level. In addition, it is also 
necessary to study how to consider infrastructure such as people, vehicles, and facilities in places where the same flooding is caused.

\section{ACKNOWLEDGEMENTS}

This work was funded by the Korea Meteorological Administration Research and Development Program under Grant KMI[2018-03010]. This work was supported by Korea Environment Industry and Technology Institute (KEITI) through Advanced Water Management Research Program, funded by Korea Ministry of Environment (MOE) (83091). This work was financially supported by Ministry of the Interior and Safety as "Human Resource Development Project in Disaster Management”.

\section{REFERENCES}

[1] Yeh, S.W., A suggestion for expanding impact prediction services. Meteorological Technology and Policy, 10(1), pp. 6-17, 2017.

[2] Flood Forecasting Centre, Flood Guidance Statement User Guide, 2017.

[3] Cole, S., Flood forecasting at national scales: Some UK experiences. National Flood Management Conference, Dublin, 2018.

[4] Price, D. et al., Operational use of a grid-based model for flood forecasting. Water Management, 165(2), pp. 65-77, 2012.

[5] Cranston, M. et al., Countrywide flood forecasting in Scotland: Challenges for hydrometeorological model uncertainty and prediction. Weather Radar and Hydrology, eds R.J. Moore, S.J. Cole \& A.J. Illingworth., IAHS Publication 351, pp. 538-543, 2012.

[6] Kim, H.M., Min, K.R., Kim, I.G., Lim, B.H., Youn, M.J. \& Kim, S.B., Paradigm shift to impact-based forecasting and warning services for natural hazard response. Korea Society of Innovation, 12(3), pp.161-178, 2017.

[7] Lee, B.J., Analysis on inundation characteristics for flood impact forecasting in Gangnam drainage basin. Korean Meteorological Society, Atmosphere, 27(2), pp. 189-197, 2017.

[8] Kim, B.S., Yoon, S.K., Hong, S.J. \& Kwon, H.H., Development of grid-based conceptual hydrologic model. Korea Water Resources Association, 42(7), pp. 667679, 2010.

[9] FLO-2D Manual, 2009.

[10] Ministry of Land, Infrastructure and Transport, Korea Precipitation Frequency Data Server, 210.92.123.136, 2011.

[11] Huff, F.A., Time distribution of rainfall in heavy storms. Water Resources Research, 3(4), pp. 1007-1019, 1967. 